\title{
A Study on the Application of Interactive English-Teaching Mode under Complex Data Analysis
}

\author{
Dongyang $\mathrm{Xu} \mathbb{D}^{1}$ and Sang-Bing Tsai $\mathbb{D}^{2}$ \\ ${ }^{1}$ Zhengzhou University of Industrial Technology, Henan 451150, China \\ ${ }^{2}$ Regional Green Economy Development Research Center, School of Business, Wuyi University, China \\ Correspondence should be addressed to Dongyang Xu; toyo0228@163.com and Sang-Bing Tsai; sangbing@hotmail.com
}

Received 3 July 2021; Revised 2 August 2021; Accepted 9 August 2021; Published 20 August 2021

Academic Editor: Yuanpeng Zhang

Copyright (c) 2021 Dongyang Xu and Sang-Bing Tsai. This is an open access article distributed under the Creative Commons Attribution License, which permits unrestricted use, distribution, and reproduction in any medium, provided the original work is properly cited.

\begin{abstract}
This research takes vocabulary learning in college English courses as an entry point and investigates the interrelationship between college students and electronic media, the presentation of interactive English-teaching content in college English, and the effect of different English-teaching modes on the effect of vocabulary learning through empirical methods in the form of network multimedia. This study provides ideas for an in-depth understanding of the incongruities that exist between interactive English teaching and environment, teacher and environment, and students and environment in the network multimedia environment and also brings thoughts on how to adapt interactive English teaching in college English to the development of modern information technology on the concept of interactive English teaching, interactive English-teaching methods, and interactive English-teaching modes. The concepts related to the adaptation of interactive English teaching based on multimedia, the compilation of the scale of adaptation of interactive English teaching based on multimedia and its influencing factors, and the construction of the model of influencing factors of adaptation of interactive English teaching based on multimedia, to a certain extent, enrich the theoretical system of learning adaptation. The design of the intervention model of adaptation of interactive English teaching based on multimedia broadens the intervention theory of learning adaptation; the study is also aimed at developing a multimedia-based interactive English-teaching adaptation intervention model and broadening the theory and method of learning adaptation.
\end{abstract}

\section{Introduction}

The rapid development of computer network technology has improved the efficiency and dynamism of work and learning and at the same time led to the reorganization of the education system and the redistribution of social education resources. Network technology will fundamentally improve the level of educational productivity, realize the integration and sharing of English-teaching resources, make way for diversified and open education, integrate the resources of education, and modernize the management of English teaching [1]. In terms of education methods, the Internet provides an interactive platform for information resource sharing, multidirectional mutual communication, and cooperative learning [2]. Through the promotion of the interactive platform, the inter- active English-teaching method in the multimedia environment has changed from single and closed to diverse and open, changing the traditional English-teaching relationship between teachers and learners in different degrees, with learners taking the main identity of learning and developing the ability of independent construction. The network is a virtual platform for information transmission, reception, and sharing. Through it, the information of various points, areas, and bodies is connected to realize the sharing of these resources. It is a tool for people to exchange and use information. As a tool, it will become easier to use, and its functions will also increase. The content will become increasingly abundant. The network will use software tools such as text reading, picture viewing, video playback, download transmission, and game chat to bring people extremely rich and beautiful use 
and enjoyment in terms of text, pictures, sound, and video. But it must be a tool of humankind. We believe that one day, the Internet will use the function of software tools to bring people extreme beauty and even surpass the feelings that the human body can bring.

In terms of the diversity and experiential nature of learning situations, the Web provides an environment related to "virtual reality" and multimedia technologies [3]. Through these technological environments, learners are "able to imitate and interpret the simulated world." In this virtual environment, learners can experience the whole process of knowledge acquisition instead of just getting facts and conclusions, and the interactive English-teaching model in the multimedia environment makes the English education environment more social and enhances learners' interest and motivation in learning [4]. At the same time, the development of the Internet has also brought about changes in the way of learning, liberating students from the traditional way of learning in which the teacher is the main body and the learners passively receive knowledge, making the way of learning diversified.

The learners can get to know diverse learning resources through the network, and on the other hand, the network provides learners with the opportunity to discover suitable learning paths for themselves and to choose suitable learning resources for learning independently [5]. Interactive English classroom English teaching in a multimedia environment is a new form of English teaching resulting from the integration of network technology and traditional classroom English teaching, with rich English-teaching resources, a multimedia form of English-teaching content, and good interactivity, which can break through the constraints of time, space, and human factors to make up for the shortcomings of traditional classroom English teaching [6]. The network-based multimedia computer-assisted English teaching provides learners with an authentic language environment, thus strengthening the learning effect and improving learners' ability of independent and collaborative learning [7].

An interactive English classroom in the multimedia environment has certain similarities with a traditional English classroom but is significantly different from the traditional English classroom. Interactive English classroom English teaching in a multimedia environment is an English-teaching tool used to accomplish English-teaching objectives by directly intervening in the English-teaching process with the computer as the main English-teaching media in the network environment. As shown in Figure 1, it integrates text, sound, graphics, images, animation, and video, with high density, high capacity, relatively strong intuitiveness, and interest, and is not limited by time and space and can be multifunctional with all-around real virtual situations, providing an interactive space for English teaching and learning, as well as providing personalized learning services to learners.

\section{Related Work}

With the further acceleration of the process of education informatization, attention is beginning to be paid to new interactive learning methods. Among them, multimedia, as a new online course form that has emerged in recent years,

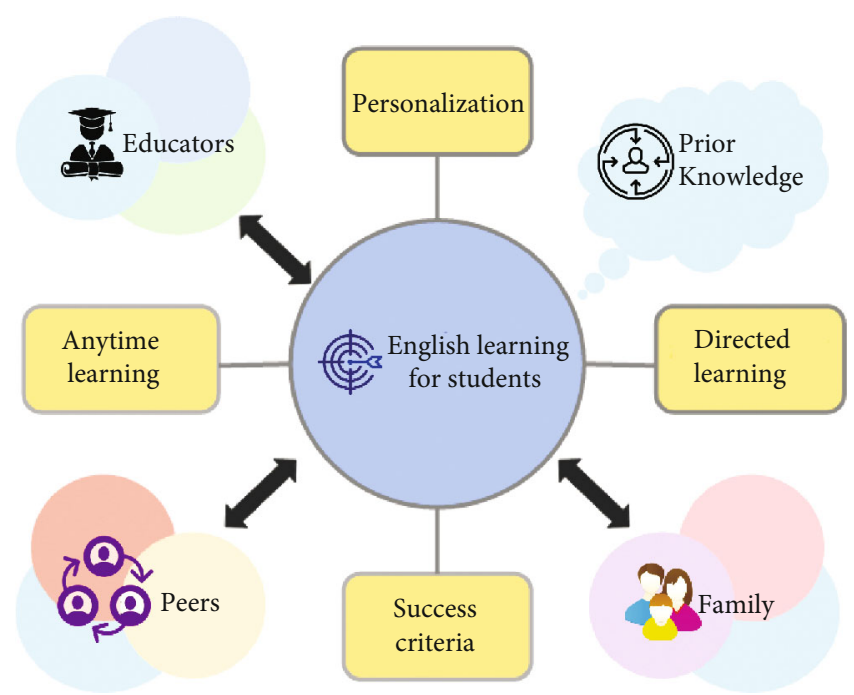

FIgURE 1: A multimedia-based model of an adaptive intervention for teaching English in an interactive English classroom.

is the latest achievement in the development of education informatization and provides new ideas and methods for the development of interactive learning in colleges and universities. At present, the use of multimedia courses for online and offline interactive learning is widely used in English teaching in colleges and universities and has been widely adopted and recognized by many schools and teachers. Therefore, the laws of teaching and learning in multimedia-based interactive learning environments have gradually become the focus of scholars' attention to promote further reform of English language teaching in higher education through the design of scientific English-teaching models and learning activities. Ma et al. investigated a blended learning model that integrates multimedia into the traditional classroom [8]. It analyzed the benefits of integrating multimedia with classroom ELT, as well as the barriers to successful multimedia implementation. Qiao and Wang applied multimedia resources to traditional ELT for interactive learning and designed corresponding learning activities [9]. The three components include online student self-paced learning, offline focused collaborative learning, and online deepening learning. Based on the Coursera Englishteaching platform, it designed a multimedia-based interactive learning model by combining face-to-face classroom English teaching and multimedia-based online learning and applied it in the English-teaching practice. Li designed a multimediabased interactive English-teaching model, in which the learning activities on the online multimedia platform include watching videos and participating in discussions, and the offline faceto-face learning activities include teacher-student interaction and discussion and question-answer [10]. On this basis, he proposed a flow of interactive multimedia-based learning activities, including three parts: online student-oriented multimedia learning, offline teacher-led classroom English teaching, and online review after class.

Learning motivation has been a hot topic in interactive learning research, with research topics focusing on the measurement of learning motivation, factors influencing 
learning motivation, the impact of learning motivation on learning outcomes, and the role of interactive learning in influencing student motivation [11]. For example, the results of Yagci's study showed that the support of course tools had a significant positive effect on learning motivation. Ling et al. analyzed the effect of learning motivation on students' learning outcomes [12]. Ma and Tsai's study also showed that learning motivation has a significant impact on students' learning effectiveness [13]. Miguel found through his study that students involved in interactive learning have higher motivation compared to face-to-face learning. Research on self-efficacy has been conducted on the effects of self-efficacy on students' learning effectiveness and the effects of interactive learning on self-efficacy. For example, Mo et al.'s study showed that multimedia-based interactive learning was effective in increasing ethnic precollege students' self-efficacy in English learning [14]. Abdelraheem's study also showed that the interactive learning approach increased students' learning efficacy. Xu and Ma studied the effect of online self-efficacy on students' learning satisfaction [15]. Ivanova's study found that students' self-efficacy was a significant predictor of learning strategy use and learning performance [16]. In the study of the psychology of learning in interactive learning environments, learning adaptation is an important research component that emphasizes the adjustment of students' attitudes, emotions, behaviors, and other elements in the learning process, which involves many psychological and behavioral elements.

The interrelationship between information technology and the degree of awareness of this and learning in the college student population is a topic that deserves attention and research. English teaching is a complex activity involving pedagogy, psychology, communication, etc. $[17,18]$. The integration of network multimedia technology has brought about great changes in teaching and learning modes and means and made English teaching more complex [19]. Based on the author's many years of experience in teaching and practicing multimedia English in college English, this study focuses on each element of classroom English teaching and the relationship between them and adopts a systematic approach to the process of teaching English in college English classrooms, especially from a holistic perspective to demonstrate the use of modern information technology in college English teaching and the problems that arise in college English-teaching reform, and we analyze the causes, clarify the dysfunctions, and propose optimization strategies [20]. The study also uses various linguistic theories, English-teaching theories, information-processing theories, and psychological theories to demonstrate the interrelationship between contemporary university students and electronic media, the influence of English-teaching presentation on vocabulary learning in the form of online multimedia, and the influence of university English-teaching modes and learning styles on vocabulary learning [21]. The scope of this study covers many aspects of English teaching in the classroom, and the research approach is distinctly comprehensive. This study can provide useful guidance and reference for teachers to change the concept of English teaching, clarify the dysfunctional phenomenon, improve the way of teaching English as a foreign language in college, and enhance the effectiveness of English teaching.

\section{Evaluation of a Model of Factors Influencing the Adaptability of Interactive English Teaching Based on Multimedia Environment}

3.1. The Design of the Model of Factors Influencing the Adaptability of Interactive English Teaching Based on Multimedia Environment. The theoretical basis of online teaching is the constructivist learning theory. The constructivist learning theory believes that students are the main body of the learning process and the active constructors of meaning. The acquisition of knowledge is not obtained through teaching, but learners obtain through active meaning construction under certain circumstances. One of the main theoretical foundations of traditional teaching is Ausubo's "learning and teaching" theory. Ausubo believes that teaching theory should consider problems in teaching practice. The content of the "learning and teaching" theory he put forward mainly involves three aspects: "meaningful acceptance of learning" theory, "advanced organizer" teaching strategy, and "motivation" theory. The main factors of the network teaching model are teachers, students, teaching content, teaching media, teaching, and learning support platform. In this teaching mode, teachers select teaching content according to the requirements of the syllabus, the characteristics of the students, and the cognitive foundation of the students; then design and compile them into multimedia teaching software, network courseware, or network courses; and publish them to the curriculum center. Students connect to the course center through the computer network, register and $\log$ in, and choose courses to study.

The components of learning adaptability in a general interactive English-teaching environment mainly include four dimensions: learning attitude, independent learning ability, learning environment, and physical and mental health. According to the characteristics of multimedia, which emphasizes communication and interaction, and the richness and diversity of learning resources and learning activities, this study adds the dimension of "learning communication" and appropriately revises the connotation and composition of the other dimensions mentioned above. Based on the literature, this study formed a five-part structure of multimedia-based interactive English-teaching adaptability consisting of learning attitude, independent learning ability, learning communication, learning environment, and physical and mental health. The connotation and composition of each dimension are analyzed below. The multimedia-based interactive Englishteaching adaptation scale and the learning adaptation influencing factor scale were reconstituted into a new scale and distributed to students. The study first tested the overall and individual dimensional levels of college students' multimediabased interactive English-teaching adaptation utilizing descriptive statistics and used parametric tests to analyze the variability of these data in terms of individual variables and to understand the basic situation of college students' multimedia-based interactive English-teaching adaptation. After that, we explored the logical relationships among the influencing factors of learning adaptation and the effects of each influencing factor on learning adaptation and constructed a model of influencing factors of learning adaptation. 


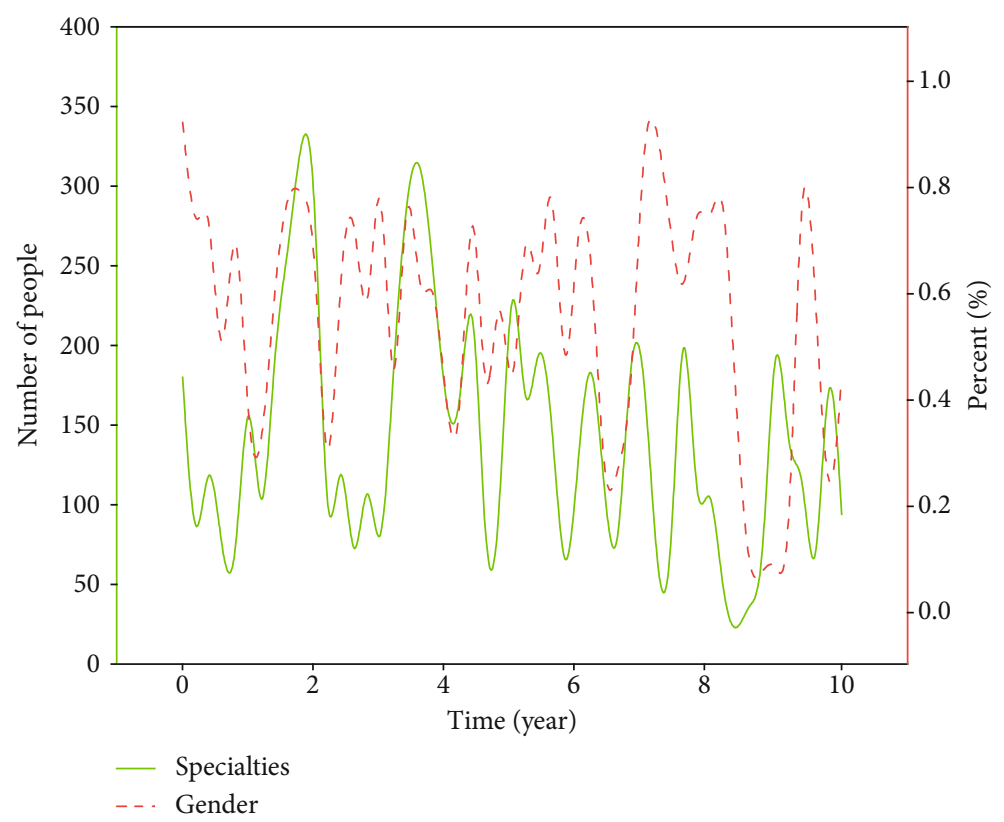

FIGURE 2: Statistics of basic information of survey respondents on the factors influencing the adaptability of interactive English teaching based on multimedia.

In terms of data information, a total of 852 questionnaires were distributed, including 483 paper questionnaires and 369 electronic questionnaires. A total of 836 questionnaires were collected, and after removing the invalid questionnaires with short answer time, missing options, choosing the same option in the whole questionnaire, and those with regular choices, 628 valid questionnaires were left, with an efficiency rate of $7.12 \%$. In terms of basic information, it mainly includes gender, major, grade, Internet age, time of exposure to multimedia, and frequency of learning courses every month. The specific statistical results are shown in Figure 2.

Among the students who participated in this survey, in terms of gender, $22.6 \%$ of the total number are male students and $77.4 \%$ of the total number are female students. In terms of majors, $56.6 \%$ of the total number of students were in the field of literature and history, $36.5 \%$ in the field of science and technology, and $7.9 \%$ in the field of art. In terms of grades, first-year students accounted for $12.1 \%$ of the total number of students, sophomores accounted for $66.7 \%$ of the total number of students, juniors accounted for $18.0 \%$ of the total number of students, and seniors accounted for $3.2 \%$ of the total number of students. In terms of the Internet age, those with 1 year or less accounted for $2.7 \%$ of the total, those with 1-2 years accounted for $10.2 \%$, those with $2-5$ years accounted for $28.5 \%$, and those with more than 5 years accounted for $58.6 \%$ of the total. Regarding the duration of multimedia exposure, $54.4 \%$ of the total number of students had been exposed to multimedia for 6 months or less, $13.1 \%$ of the total number of students had been exposed to multimedia for 6-12 months, $24.5 \%$ of the total number of students had been exposed to multimedia for 1-2 years, and $8.0 \%$ of the total number of students had been exposed to multimedia for more than 2 years. In terms of the frequency of courses per month, $21.7 \%$ of the total number of students attended 4 times or less, $33.4 \%$ of the total number of students attended $4-8$ times, $29.5 \%$ of the total number of students attended $8-12$ times, and $15.4 \%$ of the total number of students attended more than 12 times.

From the point of view of teaching methods, every student has the opportunity and freedom to do their best and show their own strengths. This has changed the boring passive classroom teaching in the past. Every student can actively participate in learning. The enthusiasm for learning is high, which embodies the teaching principle of putting people first and focusing on the development of students and interprets the teaching concept of realizing useful mathematics for everyone, and each person has a different development in mathematics. Teaching students in accordance with their aptitude, so that every student can make progress, is my greatest wish.

This section focuses on the overall as well as individual dimensional levels of college students' adaptation to multimedia-based interactive English teaching utilizing descriptive statistics analyzes the differences in individual variables of these data utilizing parametric tests to understand the basic situation of college students' adaptation to multimedia-based interactive English teaching. In statistical analysis, the mean value is generally used to measure the overall level of the variables. Utilizing descriptive statistics, the means and standard deviations of college students' adaptation to multimedia-based interactive English teaching overall as well as for each dimension were derived, as shown in Figure 3.

The standard deviations of the dimensions as well as the overall data were within acceptable limits, i.e., the dispersion of each variable was reasonable. In terms of means, the overall level of college students' adaptability to multimedia-based interactive English language teaching was moderate $(M=3.56)$, and the means of the six dimensions, in descending order, were the learning environment $(M=3.70)$, learning attitude $(M=3.60)$, 


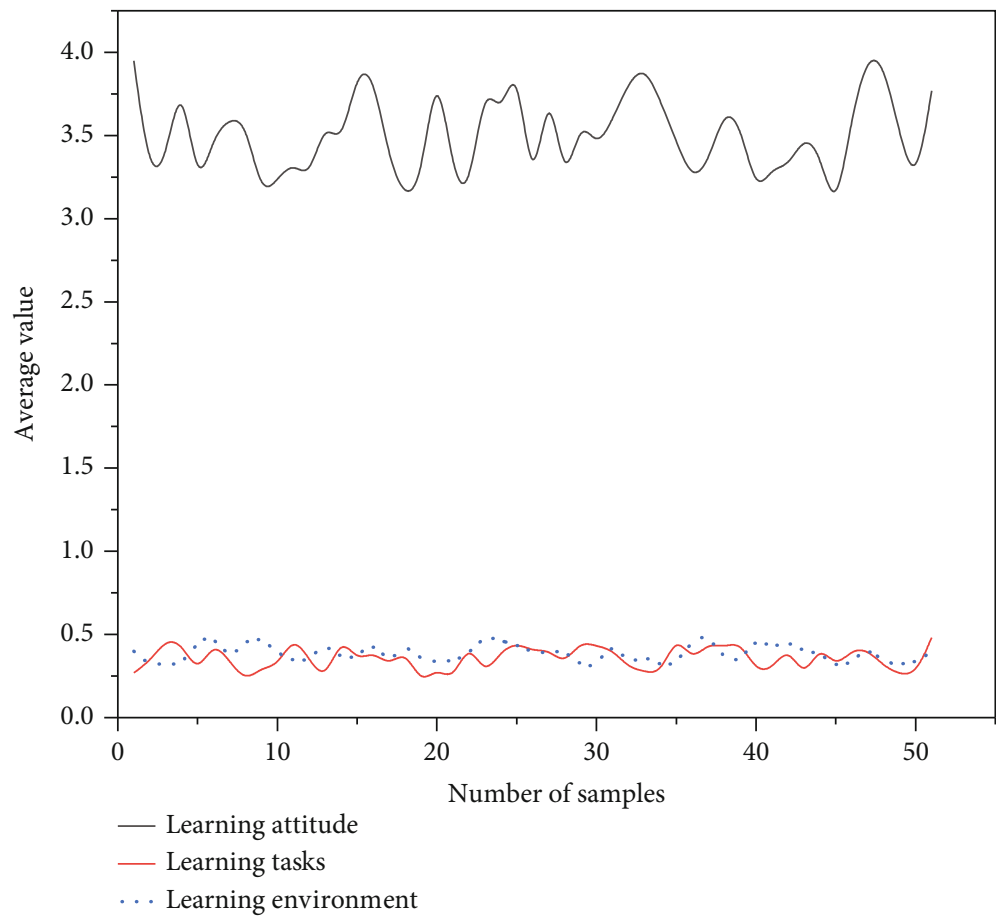

FIGURE 3: Multimedia-based interactive ELT adaptations and descriptive statistics of each dimension.

physical and mental health $(M=3.58)$, learning tasks $(M=3.57)$, independent learning ability $(M=3.47)$, and learning communication $(M=3.44)$. The results show that on specific dimensions, college students have lower scores in learning communication, independent learning ability, and learning tasks. In terms of gender, the independent sample $t$-test showed that the significant $p$ values for college students' adaptation to multimedia-based interactive English language teaching and other dimensions, except for learning communication, were greater than 0.05 , indicating no significant difference in gender. Specifically, in the learning communication dimension, male students were significantly higher than female students.

In terms of specialization, the one-way ANOVA showed that there were no significant differences in any of the dimensions except for the independent learning ability dimension and at the overall level. The Internet not only brings many changes to learning but also brings many changes to human life. First, it is reflected in the aspect of information transmission, then in the aspect of communication, and includes life, production, and learning. The significant $p$ values were $0.158,0.246,0.519,0.405 .0 .379$, and 0.725 , respectively. On the independent learning ability dimension, a post hoc comparison by the LSD method based on homogeneity of the variance test revealed that the independent learning ability scores of literature and history students were higher than those of art students $(p=0.002)$.

3.2. The Construction of a Model of Factors Influencing the Adaptability of Interactive English Teaching Based on Multimedia Environment. Based on the previous analysis, the factors influencing the adaptability of multimediabased interactive English teaching identified in this study include learning motivation, learning self-efficacy, teacher
English teaching, learning support, multimedia platform, and course content quality. Learning self-efficacy, as an important factor influencing individual learning effort, learning persistence, and self-confidence, is the key to determining the quality of students' learning [22]. Among them, learning self-efficacy is closely related to learning motivation. For example, relevant studies have shown that learning self-efficacy is an important predictor of students' learning motivation in the online environment, and students with high self-efficacy have higher learning interests and learning ambitions, which lead to better academic performance. The self-efficacy of college students has a significant positive effect on learning motivation. Students' self-efficacy significantly affects learning motivation. The previous review of the current state of research also indicates that learning self-efficacy is a key factor influencing learning adaptability. The use of computers and other multimedia for teaching is the top priority of the content of curriculum reform. Teachers can use the multiview features of computer audiovisual media to integrate teaching content and mobilize students' learning enthusiasm.

Learning support, as a set of services that guide and assist students in their independent learning, is key to determining learning outcomes [23]. Most studies have shown that good learning support can increase students' interest in learning to motivate students to study hard. It showed that learning support provided by instructors in an online environment can significantly affect college students' motivation to learn. It was also found that by providing learning support to students, teachers can stimulate students' interest and motivation to learn and improve learning outcomes [24]. A study found that faculty support had a significant impact on students' perceived importance of the knowledge 


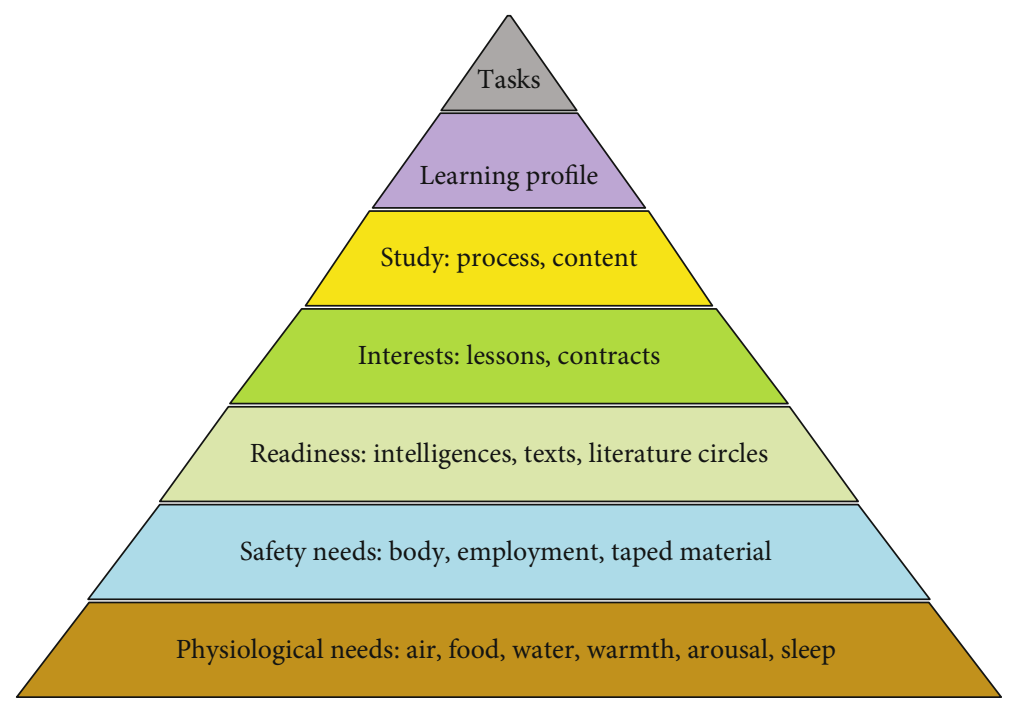

FIGURE 4: Hypothetical model of the impact of multimedia-based interactive English-teaching adaptability causal factors.

they acquired for their personal career development. Good learning support services help motivate students to learn, which in turn improves the quality of learning and thus the learning outcomes. As shown in Figure 4, the previous review of the current state of research also indicates that learning support is a key factor influencing students' learning adaptability.

The model is generally corrected according to the MI value, which indicates the minimum cardinality that the overall model will be reduced by increasing the path, i.e., the degree of improvement to the overall fitness of the model [25-27]. Therefore, attention needs to be paid to the paths with larger MI values. The principles of the correction of the model in this study include the following: the corrected index is greater than 10 , the new path should have a theoretical basis, only one path is added at a time and the degree of improvement is observed, and the correction is stopped when the model is fit. Based on completing the assessment of model fit and correction, it is necessary to test the hypothetical paths of the model proposed in this study, construct a model of the influencing factors of learning adaptability, and clarify the relationship between the influencing effects of each factor.

The difference in the lexicalization mode of sports events affects people's choice and attention to the semantic features of sports events and provides certain supporting evidence for the weak hypothesis of linguistic relativity, compared with the nongestural learning group and the multimodel with iconic gesture interpretation. The effect of attitude learning on vocabulary acquisition of students is more significant, indicating that gestures are beneficial to promote learners' cognitive processing and enhance memory representation.

As shown in Figure 5, there are two significant impact paths on multimedia-based interactive learning self-efficacy. First, learning self-efficacy has a direct effect on learning adaptability. This indicates that the more confident students are in their abilities, the better their learning adaptability will be, and thus, they will be able to overcome the difficulties they encounter in the learning process and achieve good Englishlearning results. In addition, learning self-efficacy has a significant influence on English-learning motivation and through learning motivation on learning adaptability. In other words, the more self-efficacy students have in the learning process, the stronger their motivation will be, which in turn will increase their learning adaptability and improve their learning outcomes (see Figure 5).

3.3. Validation of the Model of Factors Influencing the Adaptability of Interactive English Teaching Based on Multimedia Environment. This study applies a multimediabased interactive English-teaching adaptation intervention model for college students to English-teaching practice and adopts an action research approach to verify the practical effects of the model. Three specific rounds of action experiments are conducted, and the intervention model and its application are reflected and improved according to the implementation effects of each round, which eventually form a scientific multimedia-based interactive Englishteaching adaptation intervention model. This study applies the intervention strategies for learning adaptations to specific multimedia-based interactive English-teaching activities to test the effectiveness of the intervention. Three rounds of action research will be conducted in this study, and each round will include four components: planning, action, observation, and reflection. Through continuous practice, reflection, and revision, the learning adaptability of college students will be gradually improved. The specific design idea of the action research in this study is shown in Figure 6.

After data collection, it is also necessary to use the corresponding tools for the scientific processing of the data. First, according to the process data of this study's intervention, the processing tools corresponding to the data then include the classroom teacher-student behavior analysis coding system, the student English classroom learning engagement level analysis coding system, the SOLO classification-based learning thinking level analysis framework, the classroom teacher- 


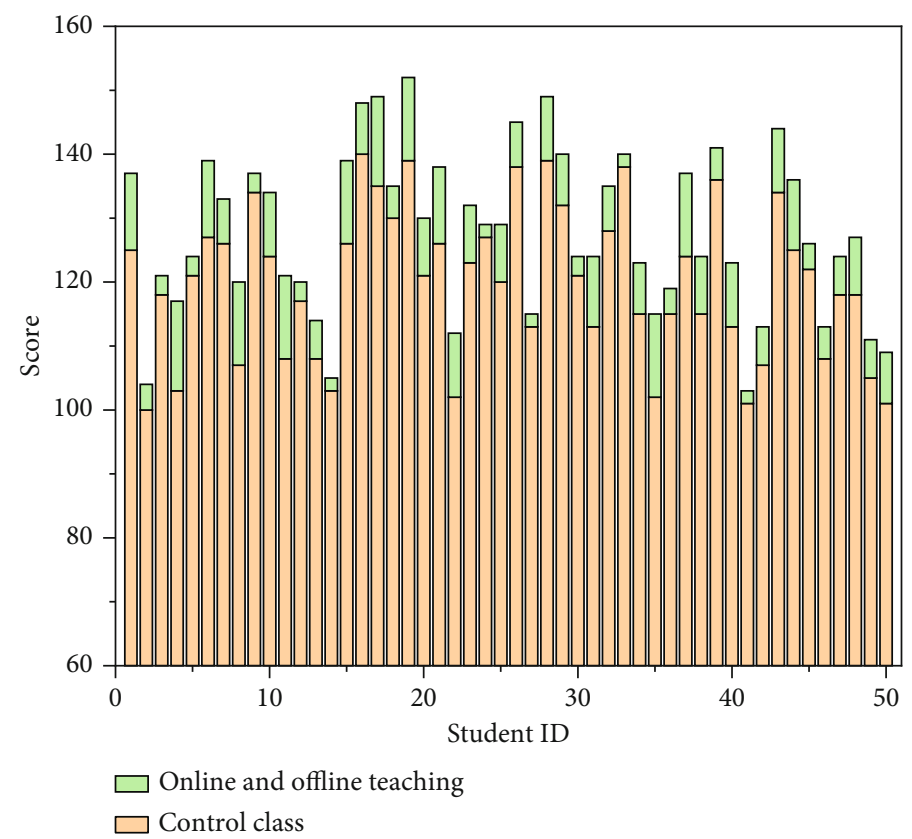

FIGURE 5: Results of the hypothesis testing of the model of factors influencing learning adaptability.

student behavior observation form, the data analysis system in the multimedia backend, and the online discussion contentcoding form [28-30]. Among them, the classroom teacherstudent behavior observation form was mainly used for the researcher to make written records during the qualitative observation. The other tools were mainly used to record quantitative observations. Second, based on the outcome data of this study's intervention, the processing tools corresponding to the data then included the multimedia-based interactive ELT adaptation scale, the unit knowledge test questions, the reflection level coding form, the student interview outline, and the teacher interview outline.

College students' learning ability and its various dimensions (knowledge acquisition and application ability, learning process self-monitoring ability, learning resource management and application ability) and various dimensions of learning motivation (learning interest, internal motivation, external motivation, achievement motivation), learning self-efficacy. There is a significant correlation. The learning interest dimension and learning self-efficacy in learning motivation have a relatively large impact on the learning ability of college students.

Based on the quantitative analysis of the discussions, a more in-depth analysis of the content of the students' discussions was conducted. Further categorization was done based on the online discussion content-coding sheet designed for this study. By counting, in the first round of intervention, there were 106 items of no substance, 387 items of resource sharing and platform operation, 85 items of insight exchange, 191 items of asking questions, 881 items of answering questions, 58 items of expressing opinions, and 48 items of feedback and comments. As shown in Figure 7, the percentage of the total number of items discussed in each category was further calculated.

\section{Multidimensional Analysis of the Path Form of English Teaching in Interactive English Classroom Based on Multimedia Environment}

4.1. Multidimensional Data Analysis of Multimedia Interactive English-Teaching Offline Process. The offline process data consisted of three sections: teacher-student teaching and learning behaviors, student response level, and student learning engagement level in classroom English teaching. This part mainly uses the classroom teacher-student behavior analysis coding system to analyze a series of behaviors of students and teachers during the class. Specifically, two main aspects of classroom teacher-student behavior distribution and classroom interaction behavior were analyzed. It should be noted here that in the first round of experiments, there were four classes, each of which lasted about 45 minutes. In this study, the classroom recordings were sampled at 3-second intervals, and according to the classroom ELT behavior analysis coding system, there was an average of 900 codes per lesson. In this study, we analyzed each lesson in detail, calculated the percentage of different behaviors, and combined it with the observation of classroom teaching behaviors to determine the structure of ELT and draw conclusions. According to the needs of the study, this section calculates eight aspects (percentages) of teacher language $(T)$, student language $(S)$, silence $(C)$, technology $(\mathrm{M})$, teacher questions $(\mathrm{Tq})$, student responses to questions (Sc), student discussion (Sd), and student questions (Sq). The statistical results of the four lessons in the first round of intervention are shown in Figure 8.

The student speech occupies a certain proportion in all four lessons, which indicates that teachers give students appropriate learning autonomy during lessons. In a comprehensive analysis, the proportion of students' speech can be 


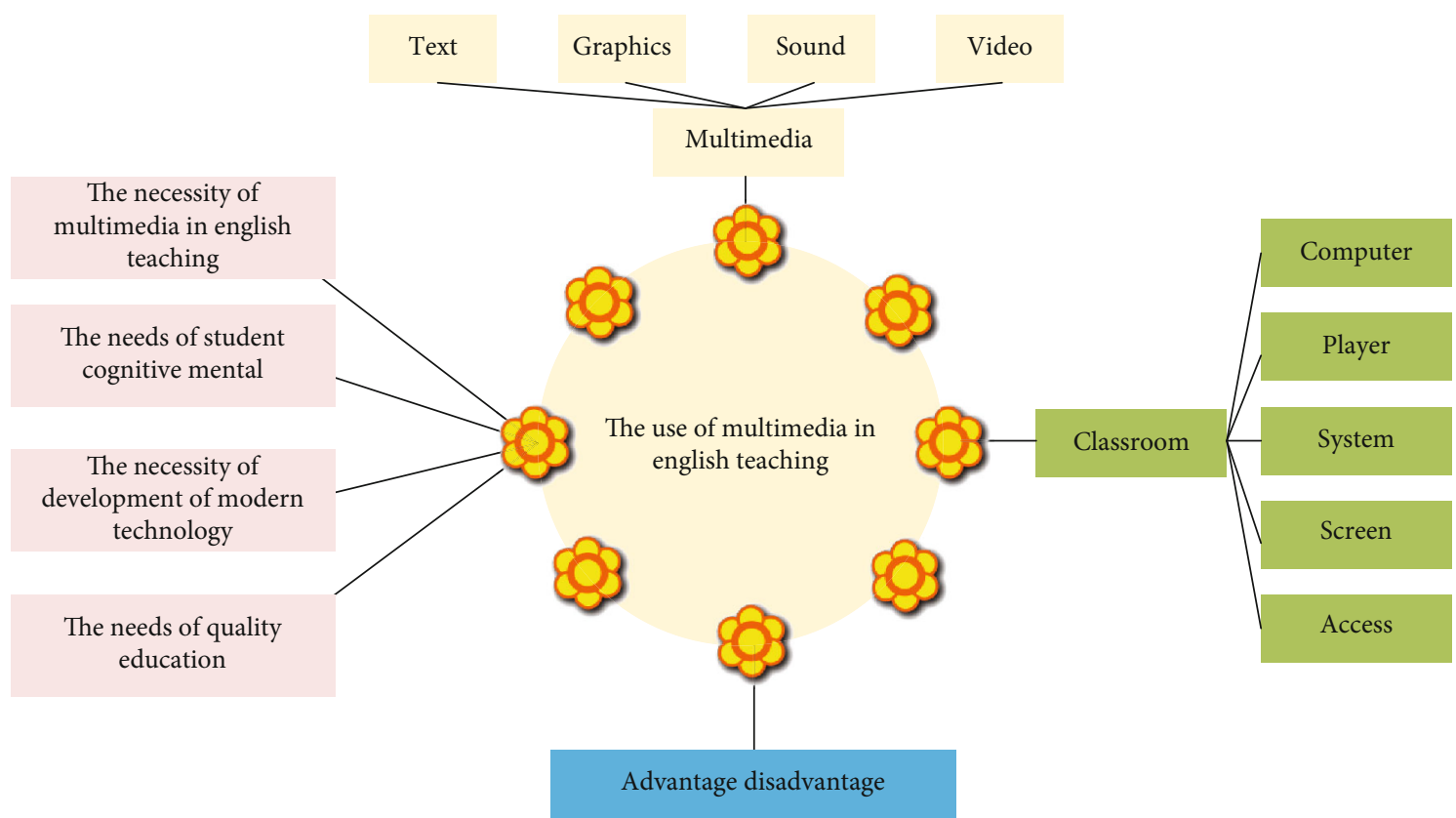

FIgURE 6: Action research design ideas for teaching English in interactive English classrooms.

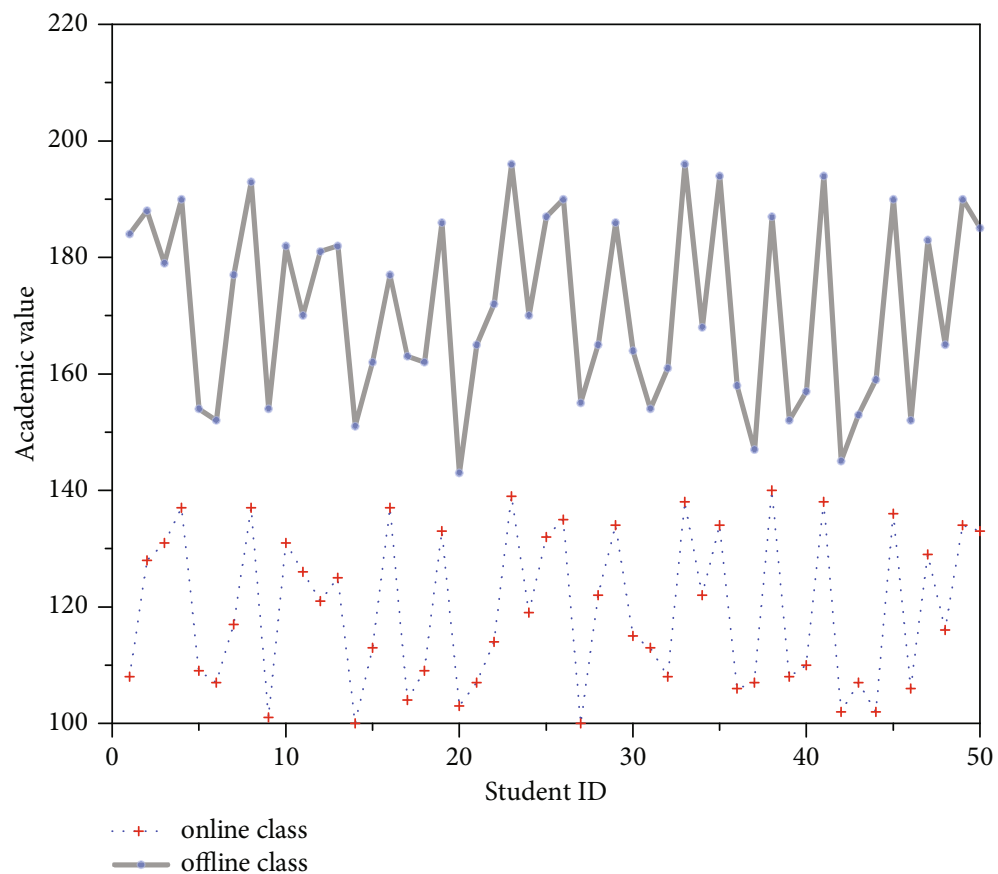

FIgURe 7: Percentage of online discussion content in English classroom English teaching in the multimedia environment.

further increased in subsequent English teaching to guarantee students' learning autonomy. In all four lessons, the teacher's questions will occupy a certain proportion, some thinking questions will be asked for students, and students will actively answer the teacher's questions. In addition, combined with the observation and review of the multimedia classroom videos, two problems can be found. We think the so-called self-learning, to put it in a more popular way, is to learn on your own. Many students do not know how to learn independently and can only follow the teacher. It is very important for students to learn to learn independently. What we are advocating is lifelong education, that is, to live and learn. This kind of education emphasizes how important learning autonomy is. First, although teachers focus on asking questions to students, they sometimes do not ask students to answer the questions and do not give them time to think. Second, after students answered the questions, they did not provide more in-depth guidance to stimulate students 


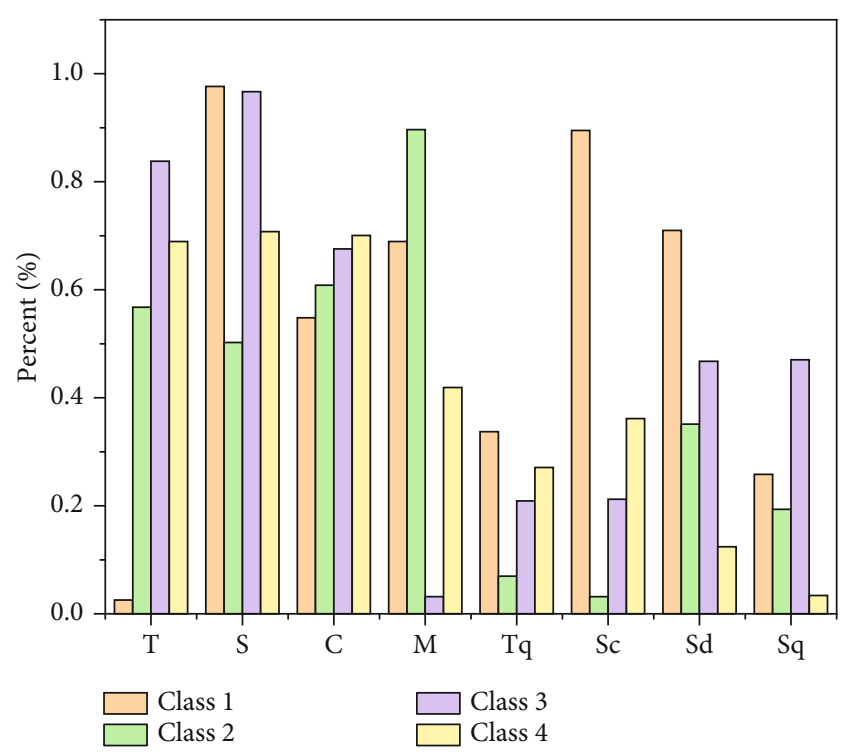

Figure 8: Distribution of teacher-student behavior and percentage of classroom interaction behavior in interactive English-teaching English classroom in the multimedia environment.

to think further about the questions. These issues need to be improved later. In contrast, the percentage of students asking questions was significantly small. Students still mainly participated passively and lacked the awareness and spirit of active inquiry and problem identification. In addition, the analysis of the video revealed that the students' motivation to participate in the classroom needs to be improved; in particular, the motivation to actively answer questions is not high enough, and sometimes, they go to answer questions and discuss at the request of the teacher.

The level of students' responses to questions is a key measure of student learning. This study analyzes the level of students' thinking in answering questions in class based on the SOLO thinking level classification framework to determine the level of students' understanding. Specifically, the number of different response levels in each lesson in the first round was calculated. As shown in Figure 9, the levels of students' responses to the questions were mainly concentrated on the two levels of single-point structure and multipoint structure (medium level), indicating that most students were able to answer the questions asked by the instructor using basic knowledge and information. The number of higher levels is low in terms of the levels of associative structure and abstract expansion structure (see Figure 9).

The overall aspect was studied for all students, and the overall student learning engagement was observed to calculate the percentage and change in the number of students at each of the three learning engagement levels over time. On this basis, the effects of the intervention were compared across different rounds. Second, on the case study side, the specific learning engagement of a subset of students was analyzed in detail, the changes in learning engagement of these students were followed up continuously, and the effects of the interventions were compared across different rounds. The four sessions were named Video 01, Video 02, Video
03, and Video 04, and each session was 45 minutes in length. To facilitate visual analysis, the study combined the time in one-minute increments (see Figure 10).

As shown in Figure 10, the learning engagement levels of most students remained at the moderate and high engagement levels throughout the ELT process, compared to the relatively small number of students at the nonengaged level, and the change was relatively flat. However, nonengaged students still occupy a certain proportion, and there are relatively more nonengaged students in some periods, which indicates that they appear to have a certain degree of low learning engagement and learning discomfort in the process of learning. It should be noted that the periods with high numbers of high engagement and nonengagement are where the most attention should be paid, so these two parts of the classroom were analyzed primarily. Further analysis revealed that students' high engagement time was concentrated in minutes 1-4, 11-15, 22-24, 35-36, and 40-42. Combined with the specific situation of the class, in minutes $1-4$, the teacher summarizes the online learning and introduces examples and introduces the lesson by asking questions, and students pay more attention. Between 11 and 15 minutes, the teacher conducts special class questions and encourages students to speak actively, and students participate in group discussions and answer questions. At 22-24 minutes, the teacher continues to ask questions and encourages students to take the initiative to ask questions. The teacher emphasizes important points to students and draws their attention to them. At 40-41 minutes, the teacher asks further questions to stimulate students to discuss and think, answer questions, and participate in interactions.

On the other hand, students' nonengagement time was concentrated in minutes 16-18, 21, 27-29, 31-34, and 4445 . In the context of the lesson, there was an intermittent decrease in students' attention in minutes 16-18 and 21, after the teacher commented on students' responses and gave answers. At minutes 27-29 and 31-34, the teacher was mainly lecturing and the content was mainly theoretical, memorized, and conceptual points. At minutes 44-45, when students were answering questions, some students did not go listen attentively. From the above, a certain proportion of low-involvement students appeared in the English teaching classroom, and the duration of high-involvement learning (high number of high-involvement) was not long, and the distribution of high-involvement learning behaviors was discrete and not continuous and concentrated enough.

4.2. Multidimensional Analysis of Multimedia Interactive English-Teaching Outcome Data. The outcome data consisted of the learning adjustment level test, unit knowledge test scores, reflection levels, student interviews, and teacher interviews. This section utilizes the learning adaptation scale developed by the study to test for changes in students' levels of learning adaptability after the intervention. Specifically, a paired-sample $t$-test was used to compare the predicted scores of the experimental students.

To analyze the learning inputs of the 30 students in detail, the study summarized the percentages of different learning input behaviors of these students to the total frequency. The 


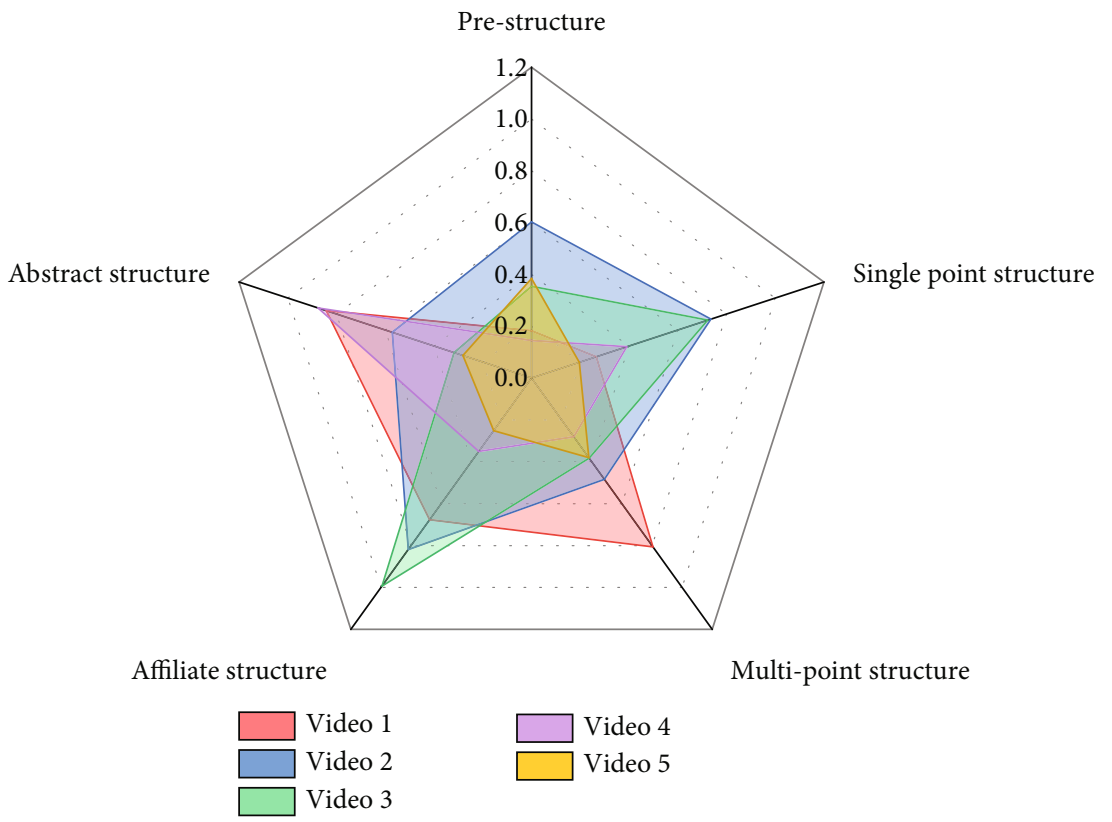

Figure 9: Percentage of students' response level in English classroom of interactive English-teaching mode.

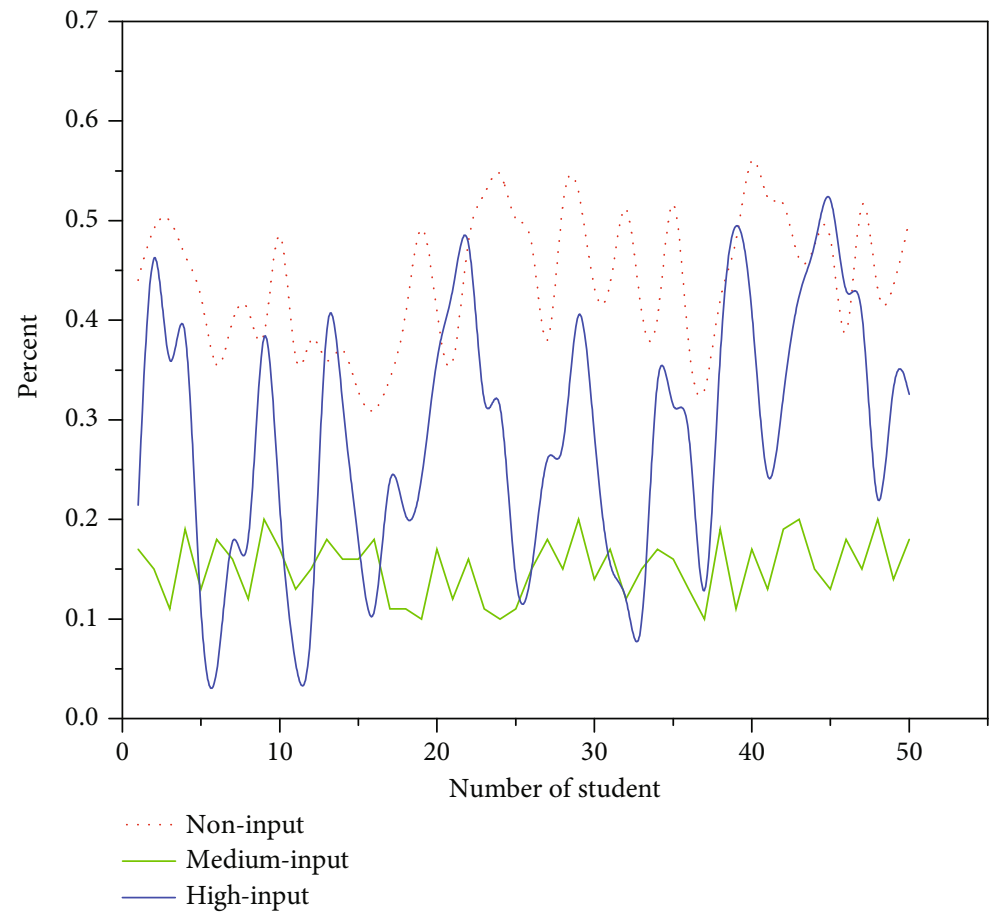

FIGURE 10: Change in the number of people with learning engagement levels over time for multimedia intervention video ELT.

distribution of learning inputs of these students can be seen more visually. Overall, in the first round of the experiment, most students had a larger percentage of moderate input behaviors versus high input behaviors. The largest proportion of moderate input behaviors indicates that moderate input was the most dominant learning input behavior among the 30 students. After that, it was the high-involvement behavior. On further analysis, the graph reveals the problem that the percentage of high-involvement behaviors of students is relatively low. The percentage of high-involvement behaviors of these students is only $18.14 \%, 13.58 \%, 19.69 \%, 21.86 \%, 21.64 \%$, and $17.28 \%$, respectively, which should be focused on. On the other hand, all 30 students showed noninvolving learning behaviors. Among them, several students had a high percentage of noninvolving behaviors. In particular, these students had $17.39 \%, 15.80 \%, 22.64 \%, 25.69 \%, 20.61 \%, 16.17 \%$, and $18.14 \%$ of noninvolving behaviors. Some students showed a significantly low percentage of high-involvement behaviors or 
a high percentage of noninvolvement behaviors, which needs to be improved in the next round of the experiment.

To more visually reflect the change in the level of reflection of the students in different rounds, Figure 1 shows the percentage of the number of students who were at different levels with no intervention and the first round and the second round of intervention. According to the graph, the number of students at low levels of reflection increased slightly through the second round of intervention. The number of people at medium to high levels of reflection increased further. This requires further strengthening of reflection instruction for students in the next round of intervention to reduce the number of low-level reflections. This study conducted three rounds of action research to verify the effectiveness of the intervention model by designing appropriate learning resources and learning activities and conducting English-teaching practices based on the learning adaptation intervention model. In each round of the study, the four steps of action research (planning, action, observation, and reflection) were strictly followed. Through the collecting process and the outcome data and corresponding data analysis, reflection was conducted on this basis to summarize the effects achieved and the shortcomings. Based on the results of reflection, the learning adaptation intervention model is further revised to provide the basis for the next round of research. This cycle of three rounds of action research basically achieved the goals set by the study, solved the corresponding practical problems, gradually improved the learning adaptability of college students, and optimized the learning effect.

\section{Conclusion}

This paper further defines the composition by developing a scale of English language-teaching adaptability and its influencing factors in English classrooms based on a multimedia-based interactive English language-teaching model through the methods of item analysis, exploratory factor analysis, and validating factor analysis. First, the learning adaptability scale was developed, which can be applied to measure the level of adaptation to multimedia-based interactive English language teaching among college students, and further defines the composition of multimedia-based interactive English language-teaching adaptability. Secondly, the development of the learning adaptation influencing factor scale can be used to further define the composition of the influencing factors of multimedia-based interactive English-teaching adaptation and lay the foundation for exploring the more complex role relationships among the influencing factors of English classroom English-teaching-learning adaptation and improving college students' learning adaptability.

This study strictly follows the four steps of action research and further revises the learning adaptation intervention model based on the reflection results, to gradually improve college students' adaptation to multimedia-based interactive English-teaching English classrooms and optimize the learning effect. First, the data is processed online, the number of student discussions gradually increased, and the proportion of discussion content such as active questions and expressing opinions gradually increased. On the offline side, the percentage of students' speech gradually increased, the quantity and quality of students' answers to questions improved, and the number of students' active questions in English classroom English teaching also gradually increased and their motivation continued to improve. The situation that high learning engagement behaviors are not long-lasting, unfocused, and discrete is gradually improving. The percentage of students' high engagement behaviors gradually increased, and the percentage of nonengagement behaviors gradually decreased. Second, the outcome data, student's level of learning adaptability, unit knowledge mastery, and reflection gradually improved over the multiple rounds of intervention.

This study developed a multimedia-based evaluation of English language-teaching adaptations in interactive English language-teaching English classrooms, which was partly reflected in the validation of the effectiveness of the intervention model of English language-teaching-learning adaptations in English classrooms. The students' process data were collected and analyzed, including the number and content of online discussions, offline classroom teachers' and students' teaching and learning behaviors, offline students' question answering levels, and offline classroom students' learning engagement levels. We collected and analyzed the outcome data of students' learning in English classrooms, including the learning adaptation level test, the unit knowledge level test, the reflection level test, and the teacher-student interviews. By comprehensively collecting students' process data and outcome data, we can not only give students scientific evaluation but also identify problems and correct intervention strategies in time, which can provide some reference for future research related to interactive English classroom English teaching in a multimedia environment.

\section{Data Availability}

All information is within the paper.

\section{Conflicts of Interest}

No competing interests exist concerning this study.

\section{References}

[1] L. Zhao, L. Chen, Q. Liu, M. Zhang, and H. Copland, “Artificial intelligence-based platform for online teaching management systems," Journal of Intelligent \& Fuzzy Systems, vol. 37, no. 1, pp. 45-51, 2019.

[2] N. Zhao, X. Zhou, B. Liu, and W. Liu, "Guiding teaching strategies with the education platform during the COVID-19 epidemic: taking Guiyang no. 1 middle school teaching practice as an example," Science Insights Education Frontiers, vol. 5, no. 2, pp. 531-539, 2020.

[3] A. Alam, "Possibilities and challenges of compounding artificial intelligence in India's educational landscape," International Journal of Advanced Science and Technology, vol. 29, no. 5, pp. 5077-5094, 2020.

[4] C. Shen, "MOOC teaching mode of news transmission based on network audio data decoding technology," International Journal of Emerging Technologies in Learning (iJET), vol. 13, no. 6 , pp. $43-55,2018$. 
[5] S. Li, "Innovations in Chinese engineering education with digital technologies: a brief review of recent advances," Computer Applications in Engineering Education, vol. 26, no. 5, pp. 10811088, 2018.

[6] W. Liu, H. L. Ma, and A. Walsh, "Advance in photonic crystal solar cells," Renewable and Sustainable Energy Reviews, vol. 116, p. 109436, 2019.

[7] X. Zhang, C. Zang, H. L. Ma, and Z. J. Wang, "Study on removing calcium carbonate plug from near wellbore by high-power ultrasonic treatment," Ultrasonics Sonochemistry, vol. 62, p. $104515,2020$.

[8] H. L. Ma, X. Zhang, F. F. Ju, and S. B. Tsai, "A study on curing kinetics of nano-phase modified epoxy resin," Scientific Reports, vol. 8, no. 1, p. 3045, 2018.

[9] F. Qiao and H. Wang, "Mobile interactive translation teaching model based on "Internet+"," EURASIA Journal of Mathematics, Science and Technology Education, vol. 13, no. 10, pp. 6705-6714, 2017.

[10] L. H. Li, "Design of college English process evaluation system based on data mining technology and internet of things [J]," International Journal of Data Warehousing and Mining (IJDWM), vol. 16, no. 2, pp. 18-33, 2020.

[11] D. Zou, H. Xie, and F. L. Wang, "Future trends and research issues of technology-enhanced language learning: a technological perspective [J]," Knowledge Management \& E-Learning: An International Journal, vol. 10, no. 4, pp. 426-440, 2018.

[12] M. Ling, M. J. Esfahani, H. Akbari, and A. Foroughi, "Effects of residence time and heating rate on gasification of petroleum residue," Petroleum Science and Technology, vol. 34, no. 22, pp. 1837-1840, 2016.

[13] H. L. Ma and S. B. Tsai, "Design of research on performance of a new iridium coordination compound for the detection of $\mathrm{Hg} 2+$," International Journal of Environmental Research and Public Health, vol. 14, no. 10, p. 1232, 2017.

[14] L. Y. Mo, W. H. Z. Sun, S. Jiang et al., "Removal of colloidal precipitation plugging with high-power ultrasound," Ultrasonics Sonochemistry, vol. 69, p. 105259, 2020.

[15] D. Xu and H. Ma, "Degradation of rhodamine B in water by ultrasound-assisted $\mathrm{TiO}_{2}$ photocatalysis," Journal of Cleaner Production, vol. 313, p. 127758, 2021.

[16] M. Ivanova, "eLearning informatics: from automation of educational activities to intelligent solutions building," Informatics in Education, vol. 19, no. 2, pp. 257-282, 2020.

[17] J. Q. Li, F. R. Yu, G. Deng, C. Luo, Z. Ming, and Q. Yan, "Industrial internet: a survey on the enabling technologies, applications, and challenges," IEEE Communications Surveys \& Tutorials, vol. 19, no. 3, pp. 1504-1526, 2017.

[18] S. Zou, "Designing and practice of a college English teaching platform based on artificial intelligence," Journal of Computational and Theoretical Nanoscience, vol. 14, no. 1, pp. 104-108, 2017.

[19] D. Gao, Y. Liu, Z. Guo et al., "A study on optimization of CBM water drainage by well-test deconvolution in the early development stage,"Water, vol. 10, no. 7, p. 929, 2018.

[20] S. B. Tsai and H. Ma, "A research on preparation and application of the monolithic catalyst with interconnecting pore structure," Scientific Reports, vol. 8, no. 1, p. 16605, 2018.

[21] J. Xie and H. Ma, "Application of improved APO algorithm in vulnerability assessment and reconstruction of microgrid," Iop Conference, vol. 108, no. 5, article 052109, 2018.
[22] S. Dai, "ARS interactive teaching mode for financial accounting course based on smart classroom," International Journal of Emerging Technologies in Learning (iJET), vol. 14, no. 3, pp. 38-50, 2019.

[23] F. Kong, J. Li, and Y. Wang, "Human-computer interactive teaching model based on fuzzy set and BP neural network," Journal of Intelligent \& Fuzzy Systems, vol. 37, no. 1, pp. 103-113, 2019.

[24] J. Kong, "Innovative applications mode of network learning space in exercise physiology based on ubiquitous learning," International Journal of Emerging Technologies in Learning (iJET), vol. 14, no. 4, pp. 113-126, 2019.

[25] Y. Zhang, Z. Zhou, H. Bai, W. Liu, and L. Wang, "Seizure classification from EEG signals using an online selective transfer TSK fuzzy classifier with joint distribution adaption and manifold regularization," Frontiers in Neuroscience, vol. 14, pp. 19, 2020.

[26] Y. Zhang, F. L. Chung, and S. Wang, "Fast exemplar-based clustering by gravity enrichment between data objects," IEEE Transactions on Systems, Man, and Cybernetics: Systems, vol. 50, no. 8, pp. 2996-3009, 2020.

[27] Y. Zhang, F. L. Chung, and S. Wang, "Takagi-Sugeno-Kang fuzzy systems with dynamic rule weights," Journal of Intelligent \& Fuzzy Systems, vol. 37, no. 6, pp. 8535-8550, 2019.

[28] T. Grubljesic, P. S. Coelho, and J. Jaklic, "The shift to socioorganizational drivers of business intelligence and analytics acceptance," Journal of Organizational and End User Computing, vol. 31, no. 2, pp. 37-64, 2019.

[29] L. X. Z. Zhang, M. Mouritsen, and J. R. Miller, "Role of perceived value in acceptance of bring your own device policy," Journal of Organizational and End User Computing, vol. 31, no. 2, pp. 65-82, 2019.

[30] A. Shahri, M. Hosseini, K. Phalp, J. Taylor, and R. Ali, "How to engineer gamification: the consensus, the best practice and the grey areas," Journal of Organizational and End User Computing, vol. 31, no. 1, pp. 39-60, 2019. 